University at Buffalo School of Law

Digital Commons @ University at Buffalo School of Law

2010

\title{
Safety Standards and Indigenous Products: What Role for Traditional Knowledge?
}

Meredith Kolsky Lewis

University at Buffalo School of Law, mlewis5@buffalo.edu

Follow this and additional works at: https://digitalcommons.law.buffalo.edu/book_sections

Part of the International Trade Law Commons

\section{Recommended Citation}

Meredith Kolsky Lewis, Safety Standards and Indigenous Products: What Role for Traditional Knowledge? in International Economic Law and National Autonomy 169 (Meredith Kolsky Lewis \& Susy Frankel, eds., Cambridge University Press 2010)

This material has been published in International Economic Law and National Autonomy edited by Meredith Kolsky Lewis \& Susy Frankel. This version is free to view and download for personal use only. Not for re-distribution, resale or use in derivative works. (C) Cambridge University Press 2010.

\section{IN COPYRIGHT}

This Book is brought to you for free and open access by the Faculty Scholarship at Digital Commons @ University at Buffalo School of Law. It has been accepted for inclusion in Contributions to Books by an authorized administrator of Digital Commons @ University at Buffalo School of Law. For more information, please contact lawscholar@buffalo.edu. 


\title{
Safety standards and indigenous products: what role for traditional knowledge?
}

\author{
MEREDITH KOLSKY LEWIS
}

\section{Introduction}

Indigenous communities have used native plants as foods and for medicinal purposes for thousands of years. Some of these indigenous products ${ }^{1}$ have proven sufficiently popular that individuals outside the indigenous community have sought to consume, purchase and market them. In certain instances, new products have been derived from the indigenous plant and sold outside the indigenous community. ${ }^{2}$ In other cases, the indigenous product has been exported in its original form, but utilized in nontraditional ways in the export market. ${ }^{3}$ In recent years, various WTO Members have imposed bans and other restrictions on the importation of certain indigenous products on the basis of health and safety concerns. These restrictions tend to be blanket bans on the products as a whole, thus curtailing both the ability to consume indigenous products according to their traditional uses, as well as the adapted versions of such products.

This chapter uses the example of the recent bans on kava from Pacific Island countries as context to argue that the safety of indigenous products with long histories of traditional use should be evaluated on their own merits. They should not be deemed the equivalent of new products with new uses that have been adapted from the indigenous plant, nor should their safety be assessed in combination with such new products. Bans on indigenous products may well be overbroad if they do not differentiate between traditional (quite possibly safe) uses and new (perhaps

${ }^{1}$ In this chapter 'indigenous products' refers to plants and products derived from plants that are indigenous to a single country or a small subset of countries.

${ }^{2}$ Kava, indigenous to the Pacific Islands and discussed throughout this chapter, is an example.

3 An example of this is the use of tea tree oil, a product derived from melaleuca alternifolia which is indigenous to New South Wales, Australia. 
not-so-safe) uses. The World Trade Organization's (WTO) Sanitary and Phytosanitary Measures Agreement (SPS Agreement) ${ }^{4}$ applies inter alia to most food safety regulations. The SPS Agreement should not be interpreted to permit Members to apply undifferentiated bans to traditional and non-traditional uses of an indigenous product. Instead, WTO Members should be required to separately assess the safety of the trad itional use so as to minimize the potential for overbroad, unduly traderestrictive regulations.

This contention may be controversial - to the extent national autonomy issues are raised in the SPS context it is generally to voice concern that national autonomy is being unduly curtailed. Commentators and government officials regularly assert that the SPS Agreement should be interpreted with significant deference to the regulating Member, so that Members can make their own decisions about risk and the safety measures necessary to suit the particular needs and desires of their populations. ${ }^{5}$ In this chapter I take a different approach, and argue that, at least in the context of the safety of indigenous plant products, there may at present be too much flexibility for Members. The kava example demonstrates that indigenous products with traditional uses are being affected by safety concerns arising from adaptations or new uses of these indigenous products. This is problematic because the traditional uses have demonstrated indicia of safety by virtue of their enduring use, yet for purposes of risk assessments and safety analyses the traditional uses are being lumped together with the new, adapted uses by overseas regulators. This chapter suggests a conceptual framework for addressing this problem so as to strike a better balance between appropriate safety measures and national regulatory autonomy.

I am not advocating changing the basic principles of the SPS Agreement, ${ }^{6}$ which allows Members to identify their own level of acceptable risk and to tailor their safety measures accordingly. Nor am I

${ }^{4}$ Agreement on the Application of Sanitary and Phytosanitary Measures, Agreement Establishing the World Trade Organization, Annex 1A, (1994) 33 ILM 1125, (15 April 1994) [hereinafter 'SPS Agreement'].

${ }^{5}$ For example, in the Hormones dispute the European Communities argued that the panel had accorded insufficient deference to the EC's SPS measures. See Appellate Body Report, European Communities - Measures Affecting Meat and Meat Products (EC - Hormones), WT/DS26/AB/R, adopted 13 February 1998, para. 13.

${ }^{6}$ As is discussed more fully in Section III, the Technical Barriers to Trade (TBT) Agreement and the GATT may also be applicable to some regulations on kava. Due to space constraints and the fact that most kava-related regulations are SPS rather than TBT measures, however, this chapter will primarily address SPS-related issues. 
suggesting that, merely because indigenous products have a long history of use, they must be safe. However, there should be some process by which the traditional use is taken into account. Otherwise indigenous products with hundreds of years of use end up being treated like brand-new products, which is inappropriate, given the different historical records the two categories of products have.

The chapter suggests that the concept of 'traditional knowledge' (TK), which in the WTO realm has thus far primarily been limited in application to the intellectual property (IP)/TRIPS context, could be applied usefully in the SPS context to differentiate the status that should be afforded to the traditional uses of indigenous products as compared with their newer, adapted uses. To the extent issue is taken with applying this IP term to the health and safety context, I would not quibble with assigning another term, so long as the intended meaning remained the same. However, I believe 'traditional knowledge' as a concept can and should translate into the SPS context, and expanding our conception of TK may assist developing countries in expanding their exports as well as providing recognition and compensation for inventions and other innov ations arising from indigenous communities. Section II of the chapter provides an overview of the Pacific Islands' experience with kava exports. Section III discusses the legal framework relevant to regulating indigenous plant products. Section IV assesses potential methods for preventing a repeat of the kava experience, and Section $\mathrm{V}$ argues that the concept of traditional knowledge should be extended to the SPS context to provide a better framework for assessing the risk of products with a history of traditional use.

\section{Too much regulatory autonomy? The Pacific Islands' kava experience}

\section{Background}

'Kava' is the name for a drink reported to have relaxant as well as other favourable characteristics, and is made from the water extracts of the rhizome or root of the Piper methysticum plant. ${ }^{7}$ Kava and kava-containing products originate primarily from Pacific Island (PI) countries, including

7 This plant has also been referred to as 'kava' and 'kava-kava', particularly in Western countries. See World Health Organization, 'Assessment of the Risk of Hepatotoxicity with Kava Products', (2007), p. 4 [hereinafter 'WHO Assessment']. 
Fiji, Samoa, Vanuatu, Tonga and Solomon Islands. ${ }^{8}$ These countries face significant obstacles to participating actively in the international trading system. All of the major kava-exporting countries are 'small island developing states', and Samoa, Solomon Islands and Vanuatu are least developed countries (LDCs). ${ }^{10}$

Kava has been used as a relaxant for many generations by the Pacific communities to which it is indigenous. The traditional use of kava, dating back hundreds of years, is to mix a powdered form of the plant root with water and to drink this mixture. ${ }^{11}$ More recently there has been interest in kava for its medicinal properties, and importing countries have made various new uses of the kava plant. Kava and kavacontaining products have been exported to overseas markets and marketed as alternatives to pharmaceutical tranquillizers and other relaxants. Unlike the water extracts traditionally used within the Pacific, in more recent years the European pharmaceutical companies have used acetone or ethanol to extract non-water-soluble, pharmacologically active, organic compounds (called kava lactones) from the kava plant, and processed them in concentrated form into capsules and pills. ${ }^{12}$ Thus European kava products have contained compounds not present in the traditional drink of water-soluble kava compounds. In addition, European companies extracted lactones from stem peelings from the kava plant - a part of the plant not commonly used to make the traditional kava drink. ${ }^{13}$

Exports of kava led to growth in the local industries, particularly in Fiji and Samoa. A significant amount of land was dedicated to growing more kava as the overseas markets expanded. ${ }^{14}$ Earnings were substantial. Fiji

8 Among the major kava exporters, Fiji, Solomon Islands and Tonga are WTO Members. Vanuatu and Samoa have not yet completed the WTO accession process and currently have observer status.

9 United Nations Office of the High Representative for the Least Developed Countries, Landlocked Developing Countries and Small Island Developing States, www.un.org/ special-rep/ohrlls/lldc/default.htm (accessed 9 December 2009).

10 The WTO recognizes as LDCs the countries so-designated by the United Nations. See 'Understanding the WTO: Least Developed Countries', available at www.wto.org/ english/thewto_e/whatis_e/tif_e/org7_e.htm (accessed 9 December 2009). The United Nations currently identifies 49 countries as LDCs. See www.unohrlls.org/en/ldc/ related/62/ (accessed 9 December 2009).

11 WHO Assessment, supra, note 7, p. 7. ${ }^{12}$ Ibid. ${ }^{13}$ Ibid., p. 8.

${ }^{14}$ Dr J. Gruenwald, Dr C. Mueller and J. Skrabal, Phytopharm Consulting, 'Kava Report 2003: In-Depth Investigation into EU Member States Market Restrictions on Kava Products - Part I: Situation Analysis', prepared for the Centre for the Development of Enterprise (Brussels, March 2003), p. I-10 [hereinafter 'Kava Report 2003']. 
was the largest exporter of kava and in the late 1990s was earning over US\$50 million per year.

\section{Alarm bells}

Although kava in its traditional drink form has been consumed in the Pacific for thousands of years without any association with liver disease, ${ }^{15}$ starting in 2000, Germany's Federal Institute for Drugs and Medical Devices, known as BfArM, drew a correlation between consumption of kava and severe liver problems. ${ }^{16}$ This ultimately led Germany, France and several other countries to ban kava imports beginning in 2002, on the basis that these products' use was correlated with hepatotoxicity, and a number of other governments followed suit shortly thereafter with bans or other regulatory restrictions. ${ }^{17}$ These actions were all primarily based on the German data and some additional reports coming from Switzerland and the United Kingdom. ${ }^{18}$ The cumulative effect was significant and, unsurprisingly, was highly damaging for the Pacific Island communities that had been generating significant sources of export income based on kava. ${ }^{19}$

On initial consideration, the bans and other restrictions may seem justified. Liver failure is a significant problem and cannot be disregarded just because the product is coming from developing countries. And indeed WTO Members are permitted under the SPS Agreement to impose import restrictions on products that have been the subject of a scientific risk assessment and deemed too dangerous to meet the levels of protection the importing country wishes to impose. The SPS Agreement also allows temporary measures to be imposed while the safety of a product is being established. ${ }^{20}$ However, on further reflection these measures raise some significant concerns.

Based on publicly available materials, it appears that in enacting these kava import bans, the importing countries did not distinguish between the safety of kava prepared in the traditional way as a drink and the safety

${ }^{15}$ Ibid., p. 5. ${ }^{16}$ WHO Assessment, supra, note 7, p. 56.

17 WHO Assessment, supra, note 7, pp. 55-6. Some countries issued warnings or voluntary recalls rather than imposing bans. Ibid., pp. 56-7. For a comprehensive summary of the measures adopted worldwide, see Kava Report 2003, supra, note 14.

18 WHO Assessment, supra, note 7, pp. 55-7.

19 For a discussion of the economic impact of the kava restrictions, see Kava Report 2003, supra, note 14, p. I-10.

${ }^{20}$ SPS Agreement, supra, note 4, Article 5.7. 
of any of the more recent pharmacological adaptations. As an example, in a 2002 notification to the WTO's SPS Committee, the United Kingdom notified emergency measures to ban kava importation and sale on grounds of food safety. The notification identifies evidencelinking consumption of medicinal kava with liver damage and then notes that it proposes to ban both medicinal and food uses of kava because 'there is no clear understanding of the nature of the hepatotoxicity, including its mechanism. Consequently, the FSA [Food Standards Agency] is proposing to prohibit food uses of Kava-kava. ${ }^{21}$ Other countries soon followed suit. ${ }^{22}$ The bans were highly controversial because of the significant adverse effects they had on the Pacific Island economies and the belief that the evidence of liver toxicity from kava was unsubstantiated. ${ }^{23}$

Thus, kava and kava products used in the traditional manner, which has a very long history of apparently safe use, were lumped together with newer, untraditional uses, and all classified as unsafe. This had devastating consequences for Pacific Island kava producers.

\section{The long road to exoneration}

Market access for traditional products is of critical importance to small states such as the Pacific Islands because these countries have only limited potential to generate export earnings. In this regard the Commonwealth countries specifically identified the kava ban as an issue that required expeditious resolution. ${ }^{24}$ Despite this urgency, Pacific Island countries had to spend several years attempting to get the bans overturned. ${ }^{25}$ The affected countries sought relief through the Africa-Caribbean-Pacific

${ }^{21}$ Committee on Sanitary and Phytosanitary Measures, 'Notification of Emergency Measures', (WTO Doc. G/SPS/N/GBR/3, 2002).

22 WHO Assessment, supra, note 7, pp. 55-7.

${ }^{23}$ See generally the historical background provided by the International Kava Executive Council (IKEC) at www.ikec.org/history/index.html (accessed 9 December 2009).

24 Abuja Communiqué, Commonwealth Heads of Government Meeting, (8 December 2003), para. 61.

25 For a chronology of the kava bans and some of the efforts to get them lifted, see Pacific Network on Globalisation, 'Lift the Kava Ban Now - Provide an Economic Lifeline for the Pacific!', (September 2007), available at www.pang.org.f/22.html (accessed 9 December 2009). This call for re-examination of kava bans and restrictions does seem to have led Germany to alter its ban in 2005, but this was only a nominal change as Germany was still determining on a case-by-case basis whether the ban for individual licences to sell kava products would be lifted. The ban on importing kava products remained intact. See, for example, M. Blumenthal, 'German Government Reconsiders Kava', HerbalGram, 67 (2005) 21; W. Morgan, 'Time to End Kava Trade Ban', Fiji Times, (23 September 2007), available at www.fijitimes.com/story.aspx?id=71049 (accessed 9 December 2009). 
(ACP) dialogue with the European Union, raising the issue at an ACP-EU Joint Parliamentary Assembly in 2004. This resulted in some cosmetic policy changes, but the bans effectively remained in place. ${ }^{26}$

The Pacific Islands Forum Secretariat, together with sympathetic European manufacturers and marketers, also established a joint representative body - the International Kava Executive Council (IKEC) - to attempt to re-establish kava trade between the Pacific and the EU. ${ }^{27}$ IKEC commissioned a study on the safety of kava and sought legal advice from the Advisory Centre on WTO Law in Geneva with respect to PI countries' rights. ${ }^{28}$

After a significant amount of agitation by various interested parties, the World Health Organization (WHO) established an expert committee to review the alleged liver toxicity effects of medicinal kava products. This report was completed in 2007 and found that 'it is clear that water extracts as taken in the South Pacific, with hardly any serious kava-related hepatotoxicity reported, are chemically different from the "kava" used to make kava pills in Europe and this difference could be responsible for the reported hepatotoxicity in some kava pill takers'. ${ }^{29}$ It concluded that the incidence of hepatotoxicity with kava is uncommon or rare, and that the small level of risk could be reduced by taking precautions such as using water-based suspensions of kava and avoiding acetonic and alcoholic extracts. ${ }^{30}$

Following the issuance of the WHO report, IKEC and others threatened to initiate WTO dispute settlement proceedings if the bans were not lifted. ${ }^{31}$ Finally, in November 2008, the European Commission lifted its ban on kava. ${ }^{32}$

26 ACP-EU Joint Parliamentary Assembly, 'Resolution on Cotton and other Commodities: Problems Encountered by ACP States', ACP-EU Doc. 3668/04/fin, adopted in Addis Ababa, (19 February 2004). This call for re-examination of kava bans and restrictions does seem to have led Germany to alter its ban in 2005, but this was only a nominal change as Germany was still determining on a case-by-case basis whether the ban for individual licenses to sell kava products would be lifted. The ban on importing kava products remained intact.

27 See generally www.ikec.org/ (accessed 9 December 2009).

${ }^{28}$ Kava Report 2003, supra, note 14; see also C. Bowman, 'Pacific Island Nations: Towards Shared Representation' in P. Gallagher, P. Low and A. L. Stoler (eds.), Managing the Challenges of WTO Participation (Cambridge University Press, 2005), p. 450, at p. 455.

${ }^{29}$ Kava Report 2003, supra, note 14, p. 8. ${ }^{30}$ WHO Assessment, supra, note 7, pp. 62-3.

31 See, for example, Radio New Zealand International (2007), 'Europe Gets One Last Chance to Lift Kava Ban before Pacific Producers Seek Help from WTO', available at www.rnzi. com/pages/news.php?op=read\&id=33852 (accessed 9 December 2009).

32 IKEC, 'Lifting the German "Ban" on Kava Exports - Outcome and Strategies of IKEC-EU Consultations', Press Release, (29 October 2008), available at www.acp-eu-trade.org/ 


\section{'Success'}

It has been suggested by some that the kava experience represents a major victory for small vulnerable states and that the regional and international cooperative efforts were a model to follow in the event of future similar conflicts. $^{33}$

On the one hand, these platitudes are of course warranted. It is a positive development that many of the bans have been lifted and that the PI economies can resume exporting lucrative products. On the other hand, however, this experience arguably should not be seen as a success story or a model process at all. It took over six years for the ban on kava products to be lifted, even with the efforts of IKEC and the Pacific Islands Forum Representative Office, both of which receive funding from developed countries. This is a very long time for small countries to be deprived of a major source of revenue, particularly given that, in the end, the traditional use of the product was essentially vindicated.

While the ultimate victory is positive, many exporters went out of business and suffered significant personal hardship. Although the European Commission lifted their ban without the need for Fiji to formally initiate WTO dispute settlement proceedings, it is deeply concerning that there was not a more streamlined way for small, vulnerable WTO Members such as Fiji to demonstrate the safety of their exports. This is particularly troubling, given that kava has been used in a traditional form for a traditional purpose for hundreds if not thousands of years. While there may have been legitimate cause for concern - even if ultimately unfounded with respect to the adapted uses of kava, it appears overbroad to assess risk based on the adapted uses, and then to apply restrictions indiscriminately to all kava products.

library/files/IKEC_EN_291008_IKEC_Lifting-the-German-ban-on-Kava-exports. pdf (accessed 9 December 2009). Although the EU lifted its kava ban, some restrictions remain elsewhere. For example, Australia still has a ban in effect, see www.bilaterals. org/article.php3?id_article=13224\&var_recherche=sparteca (accessed 9 December 2009).

33 See, for example, Bowman, supra, note 28 (discussing the benefits for the Pacific Island WTO Members of having the Pacific Islands Forum Representative Office assist with participating in WTO negotiations and resolving disputes on a regional rather than a country-specific basis); http://worldtradelaw.typepad.com/ielpblog/2008/11/kava.html (International Economic Law and Policy blog entry characterizing the lifting of the kava ban as an indication that the WTO 'can work for the little guy') (accessed 9 December 2009). 


\section{The WTO framework for regulating indigenous products}

In assessing the kava experience and how to avoid its recurrence, it is instructive to examine how the regulation of indigenous products fits within the WTO framework.

\section{Which agreement applies?}

The question of which WTO rules will apply to regulation of indigenous products depends in part on whether the products are classified as foods or drugs. If a traditional health product is deemed a food, regulations affecting its importation will fall under the SPS Agreement. If, however, the product is deemed to be a drug or medicinal product, regulations affecting its importation more likely fall under the Technical Barriers to Trade (TBT) Agreement. It is also possible that a regulation impacting traditional herbal products could fall outside the scope of the TBT Agreement (and therefore the SPS Agreement), in which case there could still be a GATT violation. ${ }^{34}$ Furthermore, it would seem that, based on the recognition of cumulative obligations under multiple WTO agreements, ${ }^{35}$ it would be possible for a regulation relating to an indigenous product to be partly an SPS measure and partly a TBT measure at the same time, and to therefore be subject simultaneously to the disciplines of both agreements. ${ }^{36}$

In practice, kava has sometimes been classified as a food and sometimes as a drug, depending on the country imposing the regulations as

${ }^{34}$ For discussions of the interplay between the SPS Agreement, TBT Agreement and GATT, see P. Van den Bossche, The Law and Policy of the World Trade Organization (Cambridge University Press, 2005), pp. 458-61; G. Marceau and J. Trachtman, 'The Technical Barriers to Trade Agreement, the Sanitary and Phytosanitary Measures Agreement, and the General Agreement on Tariffs and Trade', Journal of World Trade, 36 (2002) 811; and J. Scott, The WTO Agreement on Sanitary and Phytosanitary Measures (Oxford University Press, 2007), pp. 27-30.

35 See Appellate Body Report, European Communities - Regime for the Importation, Sale and Distribution of Bananas (EC - Bananas III), WT/DS27/AB/R, adopted 25 September 1997, paras. 221-2 (in which the Appellate Body found that both the GATT and the GATS could apply to the EC's bananas regime because the agreements have independent scope and application, and may therefore overlap). See also discussion in Marceau and Trachtman, supra, note 34, p. 863.

36 The panel in the EC - Biotech dispute found this to be the case. Panel Report, European Communities - Measures Affecting the Approval and Marketing of Biotech Products (ECBiotech), WT/DS291/R, adopted 21 November 2006, paras. 7.165 and 7.172-7.173. See also Marceau and Trachtman, supra, note 34, p. 865. 
well as the nature of the products. In a minority of countries, including Austria, Belgium, Brazil, Germany, Portugal and Switzerland, imported kava products have been largely pharmaceutical in nature and regulated as drugs. ${ }^{37}$ A larger number of countries, including Australia, Denmark, Finland, France, Greece, Italy, Singapore and Spain, have treated the kava products they import as food products and have regulated kava as a food. ${ }^{38}$ There are still other approaches. In the United States, kava products have been treated as neither foods nor drugs, but as herbal supplements or nutraceuticals, whereas Canada regulates kava as both a food and a drug. ${ }^{39}$

Notwithstanding the variety of measures described above, the majority of importing countries appear to regulate kava as a food, and almost all of the import restriction notifications were made under the SPS Agreement. Accordingly, this chapter will limit its focus to the relevant SPS issues; however, it is important to bear in mind the potential relevance of the TBT Agreement and the GATT to the regulation of indigenous products.

\section{The SPS Agreement and indigenous products}

One of the areas in which the tension between national autonomy and the need for international rules is particularly acute is that of food and drug safety-standards setting. Some of the WTO's most contentious cases, the $E C$ - Hormones and EC - Biotech disputes, have arisen in this context.

To the extent that indigenous plant-based products such as kava are regulated as foods or otherwise fall within the ambit of the SPS Agreement, such regulations must be based on a risk assessment ${ }^{40}$ which in turn must be supported by sound science. ${ }^{41}$ If there is insufficient relevant scientific evidence, Members may temporarily adopt provisional SPS measures. ${ }^{42}$ In making risk management determinations - i.e. deciding what level of protection the Member wishes to achieve - Members must, inter alia, ensure that their measures are not more trade-restrictive than necessary to achieve the desired level of protection. ${ }^{43}$

${ }^{37}$ WHO Assessment, supra, note 7, p.55.

39 WHO Assessment, supra, note 7, p. 55.

$41 \mathrm{Se}$ Obligations in the EC - Hormones Dispute(Canada/United States - Continued Suspension), WT/DS320/AB/R, WT/DS321/AB/R, adopted 14 November 2008, paras. 587-90.

42 SPS Agreement, supra, note 4, Article 5.7.

43 SPS Agreement, supra, note 4, Article 5.6.

${ }^{38}$ Ibid.

${ }^{40}$ SPS Agreement, supra, note 4, Article 5.1. of 
The SPS Agreement has an entire article - article 3 - devoted to harmonization. If WTO Members choose to base their SPS measures on international standards ${ }^{44}$ or conform their measures to such standards ${ }^{45}$ their measures will presumptively be deemed consistent with the SPS Agreement and the GATT. ${ }^{46}$ However, Members retain significant regulatory autonomy to impose measures that achieve a higher level of protection than the relevant international standard, 'if there is a scientific justification, or as a consequence of the level of sanitary or phytosanitary protection a Member determines to be appropriate in accordance with the relevant provisions of paragraphs 1 through 8 of Article $5{ }^{37} \mathrm{~A}$ footnote to Article 3.3 clarifies that 'there is a scientific justification' if, after examining and evaluating the available scientific evidence in accordance with the rest of the SPS Agreement, a Member 'determines that the relevant international standards ... are not sufficient to achieve its appropriate level of sanitary or phytosanitary protection. ${ }^{3}{ }^{48}$

Notwithstanding the text of Articles 3.1 and 3.3, the Appellate Body has rejected the view that these provisions operate as a rule and exception. In EC - Hormones, the Appellate Body explained that 'Article 3.1 of the SPS Agreement simply excludes from its scope of application the kinds of situations covered by Article 3.3 of that Agreement ... ${ }^{39}$ This interpretation has been subject to criticism as the text of Article 3.1 reads as a general obligation followed by an exception provision. ${ }^{50}$ Furthermore, the general obligation/exception structure appears in both GATT Article III and Article XX, yet the Appellate Body declined to recognize this structure in SPS Agreement Article 3. ${ }^{51}$ Instead, the Appellate Body elected to interpret the harmonization language of Article 3.1 as aspirational rather than mandatory: 'It is clear to us that harmonization of SPS measures of Members on the basis of international standards is projected in the Agreement, as a goal, yet to be realized in the future. ${ }^{52}$ Thus although

44 SPS Agreement, supra, note 4, Article 3.1.

${ }^{45}$ SPS Agreement, supra, note 4, Article 3.2.

${ }^{46}$ Ibid. ${ }^{47}$ SPS Agreement, supra, note 4, Article 3.3.

${ }^{48}$ SPS Agreement, supra, note 4, Article 3.3 n.2.

49 EC-Hormones, supra, note 5, para. 104.

${ }^{50}$ W. J. Davey, 'Reflections on the Appellate Body Decision in the Hormones Case and the Meaning of the SPS Agreement' in G. A. Bermann and P. C. Mavroidis (eds.), Trade and Human Health and Safety (Cambridge University Press, 2006), p. 118, at p. 120. Davey argues (pp. 124-5) that this interpretation strips Article 3.1 not only of its logical meaning, but of any significant meaning at all. If 3.1 is actually optional, then it is unclear why Article 3.3 is needed.

${ }^{51}$ See ibid.; Appellate Body Report, EC - Hormones, supra, note 5, paras. 103-9.

52 Appellate Body Report, EC-Hormones, supra, note 5, para. 165. 
Article 3.1 states that Members 'shall' base their SPS measures on international standards where they exist, in practice Members may set standards higher if they determine the Codex or other international standards do not satisfy their own acceptable level of protection and there is a scientific justification for therefore applying a higher standard.

The SPS Agreement thus provides Members with a significant degree of regulatory autonomy to impose stringent safety measures, so long as the level of protection can be linked to a risk assessment. In the context of the kava bans, there are a number of uncertainties in this regard. Would a ban of all kava products be deemed sufficiently based on a risk assessment that showed potential correlations between new kava products and liver damage? Would the application of the ban to all kava products fall within the scope of the Member's policy space to manage risk? Or would such a ban be deemed more trade restrictive than necessary? The EC-Hormones and United States/Canada - Continued Suspension reports suggest there must be direct links between the particular product (in those cases, specific hormones) and the particular product the Member seeks to minimize, ${ }^{53}$ but a scenario akin to that posed by the kava situation has yet to be adjudicated.

Whether or not the SPS Agreement is sufficiently clear on this point, the kava experience signals that additional efforts should be considered to ensure that domestic regulations are not overbroad with respect to products that have multiple uses. In other words, regulations should be sufficiently narrowly tailored to only reach a harmful use of a product, rather than also capturing safe, alternative uses of the same product. For example, if a blend of A and B is toxic, it would seem appropriate to ban the use or sale of $A$ and $B$ together, but it would be overbroad to ban both $\mathrm{A}$ and $\mathrm{B}$ as toxic substances, even when sold separately. This concern is particularly acute in the context of indigenous products, as the long history of traditional use strongly suggests at least some measure of safety.

\section{Potential solutions for indigenous products}

It is well documented that developing countries and small economies face a variety of challenges - both structural and financial - in their efforts to comply with SPS measures imposed by importing countries. ${ }^{54}$ Most of the

53 Canada/United States - Continued Suspension, supra, note 41, paras. 556-64 (discussing $E C-$ Hormones and the level of specificity required).

${ }^{54}$ See, for example, B. Shakya, 'Nepal: Exports of Ayurvedic Herbal Remedies and SPS Issues' in Gallagher et al., supra, note 28, p. 430 (using the example of good manufacturing practices (GMP) applicable to ayurvedic herbal remedies). 
attention has focused on the costs of establishing food safety procedures that will satisfy would-be importers. ${ }^{55}$ However, these countries can also experience a different form of obstacle when importing countries determine that the products at issue are inherently unsafe, rather than tainted or at risk of taint. Under this scenario, developing countries can find their precious export markets disappear overnight, and the process of demonstrating actual safety and rebuilding trust can be difficult and lengthy. While Aid for Trade and other capacity-building efforts have been used to address the former problem, the latter has not received much attention. Yet we should also be concerned about - and attempt to ameliorate - the burdens overbroad safety determinations impose on fragile exporting economies.

As the kava saga demonstrates, there are good reasons to assess the safety of the traditional uses of indigenous products separately from the safety of newer, adapted uses. In particular, a risk assessment of an indigenous product which has a traditional use should assess the risk from the traditional use separate and in addition to, rather than aggregated together with, the assessment of risk from the adapted uses. To permit Members to do otherwise tilts the regulatory autonomy balance too far towards sovereignty at the expense of the legitimate expectations of particularly vulnerable members of the trading community. I am not proposing revisiting the right of members to set their own desired levels of risk, nor advocating scrutiny of the legitimacy of such levels nor of the policies underlying them. Instead I am suggesting that measures that aggregate risks of indigenous products in their traditional and adapted forms run a significant risk of being more restrictive than necessary. This section canvasses various options for addressing the problem of overbroad SPS measures in the indigenous products context, beginning with dispute settlement, which, although a valuable option, has its own limitations.

\section{Dispute settlement}

It seems likely that Fiji ${ }^{56}$ could have successfully challenged the European regulations in a WTO dispute settlement proceeding as violating the SPS

55 See, for example, J. E. Stiglitz and A. Charlton, Aid for Trade: A Report for the Commonwealth Secretariat (2006), p. 17, available at http://works.bepress.com/cgi/ viewcontent.cgi?article $=1008 \&$ context $=$ joseph_stiglitz (accessed 9 December 2009) (noting that Hungary spent over $\$ 40$ million to improve the sanitation levels in its slaughterhouses in order to comply with importing members' SPS measures).

56 Fiji is the WTO Member most affected by the kava bans. The other countries most significantly affected - Samoa and Vanuatu - have yet to complete the WTO accession process 
Agreement for being more trade restrictive than necessary and, perhaps, for failing to align risk assessments with the measures taken. For developing countries, however, it is problematic to need to initiate dispute settlement to obtain market access. They face obstacles in the form of lack of resources, expertise and sufficient staffing, and fear of reprisal from aid donors, which may render it difficult or undesirable to initiate disputes. ${ }^{57}$ In addition, smaller and poorer countries do not have the economic wherewithal to retaliate in any significant way in order to induce compliance, in the event that the respondent member fails to comply with an adopted report. ${ }^{58}$ To the extent that dispute settlement is contemplated, however, the obstacles present in initiating a WTO dispute alleging violations of the SPS Agreement are all the higher due to the complexity and uncertainty of the legal, factual and scientific issues. ${ }^{59}$ In light of the Appellate Body's recent decision in the Canada/United States - Hormones Suspension case, in which it imposed a more deferential standard of review of members' SPS measures than had been applied in recent cases, it would be even more difficult for countries such as Fiji to challenge the EU's SPS measures. The Appellate Body indicated that the proper inquiry in reviewing a risk assessment undertaken pursuant to SPS Agreement Article 5.1 is 'not to determine whether the risk assessment undertaken by a WTO Member is correct, but rather to determine whether that risk assessment is supported by coherent reasoning and respectable scientific evidence and is, in this sense, objectively justifiable'.${ }^{60}$ In addition, a panel should determine 'whether the particular conclusions drawn by the Member assessing

and thus could not resolve this problem themselves through WTO dispute settlement processes.

57 For a discussion of the costs and effort involved for a developing country to initiate a dispute, see D. Tussie and V. Delich, 'Dispute Settlement Between Developing Countries: Argentina and Chilean Price Bands' in Gallagher et al., supra, note 28, p. 23; see also C. P. Bown and B. M. Hoekman, 'WTO Dispute Settlement and the Missing Developing Country Cases: Engaging the Private Sector', Journal of International Economic Law, 8 (2005) 861, p. 866.

58 Scott, supra, note 34, p. 307; Bown and Hoekman, supra, note 57, p. 866; S. Charnovitz, 'Rethinking WTO Trade Sanctions', American Journal of International Law, 95 (2001) 792. In light of this problem Antigua recently sought and obtained permission to 'crossretaliate' by suspending TRIPS obligations in a dispute involving services commitments; however, Antigua has not as yet suspended any such obligations. See Panel Report, United States - Measures to Control the Cross-border Supply of Gambling and Betting Services, Recourse to Article 21.5 of the DSU by Antigua and Barbuda, WT/DS285/RW, adopted 22 May 2007.

59 Scott, supra, note 34, p. 308.

${ }^{60}$ Canada/United States - Continued Suspension, supra, note 41, para. 590. 
the risk find sufficient support in the scientific evidence relied upon' and whether "the results of the risk assessment "sufficiently warrant" the SPS measure at issue'. ${ }^{61}$ While this decision has been applauded by many as restoring deference to national regulatory autonomy to an appropriate level, at the same time it will make it more difficult for WTO members such as Fiji to demonstrate the WTO-inconsistency of measures such as the kava ban.

\section{Harmonization}

One possible answer to the problem of overbroad SPS measures would be to increase harmonization. One of the common arguments in favour of more standardization in the SPS context is that it will improve developing countries' ability to export. However, this appears to be borne out in practice only if the standardized approach is not too stringent. The existence of a Codex Alimentarius Commission (Codex) standard does not preclude countries from adopting higher standards if they can satisfy the requirements of the SPS Agreement. The EU adopts standards which apply across the EU and can thus be considered 'harmonized' but which may significantly exceed international standards. Empirical research has suggested that when this occurs, world exports, particularly from developing countries, are likely to decrease. If instead the EU were to adopt Codex guidelines in the form of an international standard, world exports would be more likely to rise significantly. ${ }^{62}$ This research suggests that, while harmonized food safety standards can lead to increased exports from developing countries, if the harmonized standard is set at a very high level it may negatively impact the ability of developing countries to export. ${ }^{63}$

The most broadly applicable method of harmonization would be for Codex to develop more safety standards for indigenous products. ${ }^{64}$ The

${ }^{61}$ Ibid., para 591.

62 J. S. Wilson and T. Otsuki, 'Food Safety and Trade: Winners and Losers in a NonHarmonized World', Journal of Economic Integration, 18(2) (2003) 266, pp. 284-5.

${ }^{63}$ Ibid., p. 285. For a discussion of other implications of 'regulatory export' from stronger to weaker countries, see, for example, K. Raustiala, 'The Architecture of International Cooperation: Transgovernmental Networks \& the Future of International Law', Virginia Journal of International Law, 43 (2002) 1; A.-M. Slaughter, 'Sovereignty and Power in a Networked World Order', Stanford Journal of International Law, 40 (2004) 283, pp. 293-7 (discussing Raustiala's findings).

${ }^{64}$ Codex is jointly run by the World Health Organization and the UN's Food and Agriculture Organization. It establishes international standards for food regulations 
WTO Committee on Sanitary and Phytosanitary Measures monitors 'the process of international harmonization and coordinate[s] efforts in this regard with the relevant international organizations'. ${ }^{65}$ WTO Members are encouraged to play an active role in these organizations, which include Codex. ${ }^{66}$

The SPS Agreement encourages harmonization of standards and when a member's food safety regulation is based on a Codex standard it will be presumed to be consistent with the SPS Agreement. If an indigenous product is deemed a food, the producers therefore will need to be aware of whether Codex has established any standards relating to the product. Indeed, at present, the kava-producing countries are seeking to have Codex establish standards for kava as it is traditionally used. ${ }^{67}$ Codex could agree to do this if it accepts the traditional use of kava as a food. ${ }^{68}$

Codex standards may or may not be helpful to the producers of indigenous products. First, developing countries may not have participated adequately in the standards-setting process ${ }^{69}$ Because their voices are not always heard, a disconnect can result between standards established and the way products are used in the real world. Yet even without their participation, domestic product standards that conform to international standards are presumed to be consistent with WTO obligations. Notably in the EC-Sardines dispute, the Appellate Body confirmed this understanding with respect to Codex rules, even where adopted by a bare majority vote that might not have included the support of the WTO Members involved in a given dispute. ${ }^{70}$ Joel Trachtman has cautioned that 'these types of quasi-legislation, delegated by the WTO to these other bodies, present important questions about democratic accountability, and about the capacity of developing states to participate. ${ }^{71}$

such as the acceptable levels of contaminants that can be present and other types of quantitative criteria. See generally www.codexalimentarius.net/web/index_en.jsp (accessed 9 December 2009).

65 SPS Agreement, supra, note 4, Article 3.5.

66 SPS Agreement, supra, note 4, Article 3.4.

67 See Joint FAO/WHO Food Standards Programme, 'Discussion Paper on the Development of a Standard for Kava', CX/NASWP/08/10/7 (September 2008).

68 The Pacific Island countries are not seeking to have Codex weigh in on the pharmacological uses because those uses fall outside Codex's jurisdiction of food safety.

69 See generally, Food and Agriculture Organization of the United Nations, 'The Dynamics of Sanitary and Technical Requirements: Assisting the Poor to Cope’, (Rome, 2005), available at www.fao.org/docrep/009/a0011e/A0011E00.htm - TOC (accessed 9 December 2009).

70 Appellate Body Report, European Communities - Trade Description of Sardines, WT/ DS231/AB/R, adopted 23 October 2002.

${ }^{71}$ Joel Trachtman, 'The Constitutions of the WTO', European Journal of International Law, 17 (2006) 623, p. 639. 
In addition, Codex standards can only address food/SPS uses, and therefore cannot resolve situations involving indigenous products with purely medicinal uses, such as tea tree oil. Some have even criticized the application of Codex rules to natural and traditional health products, arguing that these products are fundamentally different from foods and therefore the regulations may not be appropriate. ${ }^{72}$

Harmonization is probably, on balance, preferable to no harmonization, as an official international pronouncement of safe parameters is a useful benchmark to be able to point to. But because countries can adopt higher standards if they wish, harmonization cannot completely remove the problem of overbroad regulations.

\section{Recognizing traditional uses}

When assessing the safety of a product that is, or is derived from, an indigenous product, a distinction should be made between the traditional use and any relevant adapted uses. While the safety of the traditional use should not be given a free pass, it should be assessed as a stand-alone consideration, separate from the assessment of the adapted uses (whether adapted by traditional or new users).

In considering the safety of the traditional use, members are of course entitled to use traditional scientific measures of safety. However, it should be noted that there is precedent internationally for recognizing the safety of items that have been in the food supply for a long time. For example, in the United States these are called 'GRAS' or 'generally recognized as safe' items and include things such as vanilla, vinegar and caramel. ${ }^{73}$ Many years ago, a legal challenge was brought against an interpretation the US Food and Drug Administration (FDA) had made of its regulations in which it found that language which provided that food safety could be established based on 'common use in food' prior to 1958 meant 'common

72 On the other hand, these products also seem to be different from drugs. Thus some have suggested that a third category should be created whereby natural and traditional products would be subject to their own laws, distinct from those applicable to foods or medicines. This is the position of the New Zealand Health Trust, for example, which advocates for natural health and therapeutic products to be regulated as a third category of product, separate from either foods or medicines; www.nzhealthtrust.co.nz/pdf/ANZTPA Public_Briefing_Points_Summary_11_Feb_07.htm (accessed 9 December 2009).

73 See, for example, Federal Food, Drug, and Cosmetic Act (Chemical Additives in Food): Hearings on HR 4475, Before a Subcomm. of the House Comm. on Interstate and Foreign Commerce, 84th Cong., 2d Sess. 28 (1956), pp. 460-4 (statement of FDA Commissioner George Larrick). 
use in the United States. ${ }^{74}$ The court rejected the FDA interpretation and found that foreign practice could be looked at. ${ }^{75}$ Subsequently the FDA amended its food additive and drug regulations to take into account the experience of other countries in its determinations of whether a product is 'generally recognized as safe' based on a long history of use in food. ${ }^{76}$ Canada also differentiates between ordinary food products and 'novel foods', the latter of which are subject to a full review by Health Canada before they may be offered for sale. 'Novel foods' are those which, inter alia, do not 'have a history of safe use as a food'. ${ }^{7}$

The EU is currently considering repealing its Regulation on Novel Foods (Regulation No 258/97) ${ }^{78}$ to, inter alia, introduce a new procedure for evaluating traditional foods from third countries. WTO Members have previously raised concerns regarding Regulation No 258/97 and its earlier proposed amendments, arguing that the current and proposed measures impose excessive requirements to demonstrate the safety of food products with a long history of traditional use. ${ }^{79}$ In response, the EU has been evaluating a revision which would impose less onerous requirements for traditional food products from third countries with a demonstrated history of safe food use, than would be required of 'novel foods' ${ }^{80}$

Thus there is precedent for recognizing products as having a traditional use, and according such products a distinct status.

\section{What role for traditional knowledge?}

This section considers how TK could be incorporated into assessments of SPS measures.

${ }^{74}$ Fmali Herb v. Heckler, 715 F2d 1385 (9th Cir., 1983).

75 Ibid., pp. 1390-1. ${ }^{76} 21$ C.F.R. $\$ 170$ (c)(2).

77 For details on the process by which it is determined whether a product is a regular food product or a novel one, see www.hc-sc.gc.ca/fn-an/gmf-agm/pol/index-eng/php (accessed 9 December 2009). The regulatory definition of 'novel food' appears in Division 28 of the Food and Drug Regulations at CRC c. 870.

${ }^{78}$ Regulation (EC) No 258/97 of the European Parliament and of the Council of 27 January 1997.

79 WTO Committee on Sanitary and Phytosanitary Measures, Note by the Secretariat, 'Summary of the Meeting of 29-30 March 2006', (WTO Doc. G/SPS/R/40, 2006), pp. 21-9.

80 'Proposal for a Regulation of the European Parliament and of the Council on Novel Foods', COM (2007) 872 final, 2008/0002 (COD), Brussels, (14 January 2008), p. 8. 


\section{Traditional use and traditional knowledge}

As a framework for looking at the traditional use of indigenous products, I propose importing the concept of 'traditional knowledge' or TK, which has heretofore been discussed in the WTO exclusively in the context of the TRIPS Agreement and intellectual property protection ${ }^{81}$ and which is commonly used to refer to plant and genetic resources of indigenous peoples. There is no one accepted definition ofTK, but medicinal and herbal plants would seem to fall within the scope of many of the definitions. ${ }^{82}$

The TK issue is not yet even close to resolution in the TRIPS context, so it may be naïve to think it could be expanded to the SPS/TBT context. But it does seem that there is broad agreement that $\mathrm{TK}$ should be recognized. The issues are more to do with what value to assign to TK than whether it has a value, and in what contexts TK applies. If TK is recognized as having a value in the IP context, this must mean it is connected to marketable products. These products would not have marketable value if they were demonstrably dangerous. If this is the case, then perhaps for products recognized as TK, it is reasonable for that TK to be taken into account in some way in the SPS/TBT safety analysis, particularly where the product at issue has both a traditional use and new, adapted uses.

This is not so different from the way Europeans currently address the safety of raw milk cheeses and cured meats. These products in many cases are accorded geographical indications - a form of intellectual property

${ }^{81}$ For example, whether traditional knowledge should be patentable or subject to other forms of intellectual property protection. This issue is primarily being considered in the context of TRIPS Article 27.3(b), which addresses the patentability or non-patentability of plant (and animal) inventions, and the protection to be afforded to plant varieties. Pursuant to the requirements of the TRIPS Agreement, a review is being conducted of Article 27.3(b). In addition, Paragraph 19 of the 2001 Doha Declaration calls for the TRIPS Council to look at, inter alia, the protection of traditional knowledge. See, for example, World Trade Organization, Council for Trade-Related Aspects of Intellectual Property Rights, 'The Protection of Traditional Knowledge and Folklore: Summary of Issues Raised and Points Made', (WTO Doc. IP/C/W/370/Rev.1, 2006); 'TRIPS: Reviews, Article 27.3(b) and Related Issues', available at www.wto.org/english/tratop_e/trips_e/ art27_3b_background_e.htm (accessed 9 December 2009).

82 See T. Cottier and M. Panizzon, 'Legal Perspectives on Traditional Knowledge: the Case for Intellectual Property Protection', Journal of International Economic Law, 7 (2004) 371, p. 379. One definition referenced in WIPO's Operational Terms and Definitions for TK is 'accumulated knowledge that is vital for conservation and sustainable use of biological resources and/or which is of socio-economic value, and which has been developed over the years in indigenous/local communities.' See ibid., n. 37. 
protection - and are deemed safe, based on a long history of experience rather than on modern-day scientific testing. ${ }^{83}$

There are numerous possible ways TK could be taken into account in the SPS context. One possibility would be to allocate Aid for Trade or other trade-related capacity-building funding to fast-track safety analyses of the traditional uses of such products. Another option would be for the SPS Committee to develop protocols for assessing the safety of the traditional uses of indigenous products. It is beyond the scope of this chapter to assess the potential methods for taking TK into account; for present purposes I merely want to suggest that traditional knowledge could be a useful concept to import into the safety context to help prevent overbroad regulation of products that in all likelihood are safe.

\section{Culture}

The idea of using TK, or cultural knowledge, may seem inappropriate in the context of safety, which is usually seen as a scientific inquiry. However, 'culture' does play a role in scientific risk assessments. We see it most commonly in the context of regulatory autonomy, when it is often argued that deference must be given to each nation's own policy choices as to what it wants to protect against. Common examples in this respect are the policy choices of the EU and the United States with respect to health measures. The EU is far more concerned than the US over the safety of genetically modified organisms and growth hormones. In contrast, the US seems more concerned with cancer risks than the EU and also requires more detailed information on labels regarding fat content and cholesterol than does the EU. ${ }^{84}$ These policy choices reflect different cultural values.

${ }^{83}$ M. A. Echols, 'Food Safety Regulation in the European Union and the United States: Different Cultures, Different Laws', Columbia Journal of European Law, 4 (1998) 525 , p. 528. The recognition of geographical indications (GIs) for wine and spirits, and the ongoing discussions regarding expanding the scope of recognized geographical indications, reflect an acceptance that products originating from particular regions and production processes have a value that should be protected from exploitation by others. Although owners of geographical indications tend to reject a link between GIs and traditional knowledge, in fact the two seem to be highly analogous, if not the same. See S. Frankel, 'Trademarks, Traditional Knowledge and Cultural Intellectual Property' in G. B. Dinwoodie and M. D. Janis, (eds.), Trademark Law and Theory (Cheltenham, Edward Elgar, 2008), pp. 452-3.

${ }^{84}$ See, for example, B. A. Silverglade, 'The WTO Agreement on Sanitary and Phytosanitary Measures: Weakening Food Safety Regulations to Facilitate Trade?', Food and Drug Law Journal, 55 (2000) 517, p. 520 (noting EU objections to US labelling requirements). 
A further example is unpasteurized cheese. Due to the long experience in Europe with unpasteurized dairy products, unpasteurized cheese is widely available in Europe and generally considered to be safe. In the US, by contrast, pasteurization is associated with safety of dairy products and there are serious concerns about botulism and other problems being associated with unpasteurized cheese; hence, unpasteurized dairy products are heavily regulated in the US. At present the WTO permits these cultural differences by providing a degree of policy space for members to reach their own decisions as to what is worth protecting. Some would argue there is not enough policy space there, and that in particular more flexibility is needed to take into account consumer preferences and to be able to take precautionary measures even when a degree of scientific information is available.

Regardless of whether one thinks the amount of policy space or regulatory autonomy is at an appropriate level, there surely is some room to make country-specific determinations as to what levels of risk are desired for different health and safety concerns. Science is then used, in the form of risk assessments, to implement these cultural decisions. ${ }^{85}$ The EU in particular has defended its measures on grounds of consumer preference, even where scientific evidence of risk is lacking - in essence, justifying deferring to cultural attitudes. ${ }^{86}$ What I am proposing could be seen as the flip side of the equation: that culture - in the form of traditional knowledge - should be taken into account in some way in determining how we go about the scientific process of safety assessment. ${ }^{87}$ In

${ }^{85}$ In the SPS context, the WTO has been criticized for not giving sufficient weight to the cultural factors that underlie risk assessments. See generally Scott, supra, note 34, p. 3. Contextual examples have included the EC's restrictions on the importation of meat containing hormones, and EC member country restrictions on the importation of genetically modified organisms, both of which of course have given rise to contentious dispute settlement proceedings. See EC - Hormones, supra, note 5; EC - Biotech, supra, note 36.

${ }^{86}$ For example, EC - Hormones, supra, note 5, para. 245. For a discussion of the ways different cultural preferences for food safety regulation play out in the EU and the United States, see Echols, supra, note 83. See also M. Trebilcock and J. Soloway, 'International Trade Policy and Domestic Food Safety Regulation: The Case for Substantial Deference by the WTO Dispute Settlement Body under the SPS Agreement' in D. L. M. Kennedy and J. D. Southwick (eds.), The Political Economy of International Trade Law (Cambridge University Press, 2002), p. 557; H. F. Chang, 'Risk Regulation, Endogenous Public Concerns, and the Hormones Dispute: Nothing to Fear but Fear Itself?', Southern California Law Review, 77 (2004) 743, pp. 755-6 (discussing the EU's preference for a precautionary approach in the areas of health and environmental protection).

87 Joanne Scott has criticized the silencing of culture in the SPS Agreement, which she terms a technocratic zone. See 'On Kith, Kine (and Crustaceans): Trade and Environment in the EU and WTO' in J. H. H. Weiler (ed.), The EU, the WTO, and the NAFTA: Towards 
particular, when plants and plant products have a long history of a traditional, common usage as foods and/or medicines, some value should be given - some recognition afforded - to the enduring practices of the indigenous communities from which these products originate.

\section{Room for culture in risk assessment?}

Risk assessment is the first component of a risk analysis. Once the risk is assessed, the second stage is risk management where policy-makers determine what the acceptable level of risk is and how best to keep risk at or below that level. The first of these processes - risk assessment - is widely seen as a technical phase where scientific analysis is conducted. The second phase, risk management, is where value judgements are traditionally identified. ${ }^{88}$

However, it is evident that the risk assessment phase also entails some decision-making. Risk assessment generally entails four stages identified over 25 years ago by the National Research Council in the United States. These stages are hazard identification, dose-response assessment, exposure assessment and risk characterization. Codex uses very similar categories - hazard identification, hazard characterization (which includes dose-response assessment), exposure assessment and risk characterization. ${ }^{89}$ The SPS Agreement defines risk assessment similarly. ${ }^{90}$ While risk assessment is, on its surface, scientific and value-neutral, in fact scientists have to make all sorts of decisions, assumptions and other policy choices in conducting their analyses. An example would be deciding to use particular animal data to predict outcomes in humans, or to assume that the absorption rate in animals and humans is the same or close to the same. ${ }^{91}$ Indeed, these policy choices and assumptions are not consistent across regulatory bodies,

a Common Law of International Trade? (Oxford University Press, 2000), p. 125, at p. 157; see also C. Button, The Power to Protect: Trade, Health and Uncertainty in the WTO (Oregon, Hart Publishing, 2004), ch. 4 (addressing the role of culture in shaping regulatory practice).

${ }^{88}$ Button, supra, note 87, pp. 96-7. The Appellate Body has rejected a rigid distinction between these two phases and appears to view at least some aspects of risk management as being within the SPS Agreement's scope. See ibid., pp. 101-2; EC-Hormones, supra, note 5, para. 181 .

89 Button, supra, note 87, p. 96.90 See SPS Agreement, supra, note 4, Annex A.

91 Button, supra, note 87, p. 97. These policy choices are often recorded. For example, the risk assessment policies used in generating Codex standards are documented in a joint FAO/WHO Consultation, 'Risk Management and Food Safety', (FAO Food and Nutrition Paper 65, 1997), pp. 8-9 (cited in Button at p. 97 n. 17). 
meaning that different assumptions can lead to different outcomes. The risk assessment process has thus been subject to criticism as not being value-neutral in practice, and some argue the use of policy in the scientific process undermines the legitimacy of using science to assess risk as it may impact the outcomes reached..$^{92}$

Furthermore, even hazard identification may have cultural assumptions embedded into it. Europeans have been eating unpasteurized cheeses for centuries and thus do not see them as a potential hazard. Other countries with different cultural experiences may see these same products as potentially dangerous.

It would seem that it would be within the normal parameters of the risk assessment process to identify the various potential uses of the product being assessed, and to assess each potential use. Traditional knowledge can therefore be factored into the process merely by ensuring that the risk assessment includes a separate analysis of the safety of the traditional use. This would then avoid the problem of the traditional use being lumped together with the new uses. This approach would also be consistent with the Appellate Body's guidance in the EC - Hormones dispute, in which it cautioned that risk assessments should not be limited to laboratory exercises but need to evaluate 'risk in human societies as they actually exist where people live and work and die'. ${ }^{93}$

\section{SPS Committee}

It would not require any sort of wholesale changes in WTO rules or even in practice to take traditional knowledge into account. This type of understanding could be reached within the SPS Committee, which meets several times a year and discusses particular concerns of members. ${ }^{94}$ And so doing might help prevent a repetition of situations such as the six-year ban on all kava products. It would be appropriate for this recognition to take place in the SPS Committee. Given the expense and time involved in bringing a dispute, it would be much better to resolve such issues informally. It would also be in keeping with the SPS Agreement's provisions on special and differential treatment for developing countries. In particular, Article 10.1 provides: 'In the preparation and application of sanitary or

92 See discussion in Button, supra, note 87, pp. 98-9 and footnotes therein.

93 EC-Hormones, supra, note 5, para. 187.

94 Article 12 of the SPS Agreement sets forth that the role of the SPS Committee is to serve as a forum for consultations relating to SPS issues. 
phytosanitary measures, Members shall take account of the special needs of developing country Members, and in particular of the least-developed country Members.' This suggests that Members should assess the effects their SPS measures may have on developing countries, from the outset. The SPS Committee would be a useful forum for identifying traditional uses of products which Members are seeking to regulate.

\section{Conclusion}

The kava example suggests that the WTO's health and safety rules may be used by Members in a way that can lead to overly strict regulation of indigenous products. I question whether any measures can or should be taken to ensure that Members' risk assessments give weight where appropriate to traditional knowledge and product usage such that overbroad regulations are minimized. In this regard, to the extent the safety of indigenous products are being called into question based on non-traditional uses, I posit that perhaps risk assessments of indigenous products should include an assessment of the safety of the product as it has been traditionally used, separate and apart from the analysis of the product as utilized inside the importing country. The concept of traditional knowledge may be a useful tool in identifying which products should be deemed to have a sufficient history of 'traditional use' to warrant a separate safety analysis. 